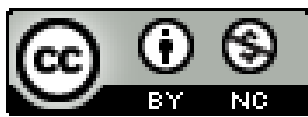

\title{
HANS JONAS E O PROFÉTICO NA FILOSOFIA: SOBRE OS 40 ANOS DE DAS PRINZIP VERANTWORTUNG
}

\author{
Hans Jonas, prophecy and philosophy: \\ About the 40 years of Das Prinzip Verantwortung
}

\author{
Wendell Evangelista Soares Lopes \\ UFMT
}

\begin{abstract}
Resumo: O presente ensaio apresenta uma análise crítica do problema do profético na filosofia a partir de uma consideração da reflexão moral de Hans Jonas em Das Prinzip Verantwortung (1979). Jonas demonstra ter seguido, bem de perto, deliberadamente ou casualmente uma sabedoria prática específica de Kant, a saber: a necessidade de fazer da filosofia um instrumento profético. O ensaio realiza, portanto, uma espécie de avaliação retrospectiva da fortuna do livro tendo em vista os seus resultados esperados, o que possibilitará de maneira secundária também uma nova aproximação da ética da responsabilidade com a filosofia da história e a reflexão moral de Kant, bem como permitirá uma avaliar também do quanto o profético vale para o filosofila.
\end{abstract}

Palavras-chave: Jonas e Kant, Responsabilidade ética, heurística do temor, profecia e filosofia

Abstract This essay presents a critical analysis of the problem of prophecy in philosophy taking as its starting point a consideration of Hans Jonas' moral reflection in Das Prinzip Verantwortung (1979). Jonas demonstrates that he followed, very closely, deliberately or not, a specific practical wisdom of Kant, namely: a need to make philosophy a kind of prophetic instrument. The essay therefore performs a kind of retrospective assessment of the book's fortune in view of its expected results, which will also make it possible, in a secondary way, to bring the ethics of responsibility closer to Kant's philosophy of history and moral reflection, as well as an evaluation also of the value of prophecy to philosophy.

Keywords: Jonas and Kant, ethical responsibility, heuristic of fear, prophecy and philosophy.

\section{Introdução}

Em 2019 se comemorou 40 anos da publicação de Das Prinzip Verantwortung (1979), livro que marcou época na Alemanha, e que elevou ao estrelato o filósofo Hans Jonas. Com esse agora famoso livro, Jonas se tornou uma referência no interior da disciplina ética. Em relação a esta disciplina, dois grandes paradigmas se estabeleceram: antes de tudo, o modelo teleológico-eudaimonista da ética aristotélica, de outro, o modelo deontológico kantiano. Costuma-se alinhar a ética de Jonas do lado do aristotelismo. Da conversa com Arendt e sua "desaprovação por completo da ideia de que a responsabilidade elementar do homem pudesse estar fundada biologicamente a partir da ordem natural", Jonas tomou consciência de que seu livro teria um destino solitário, e que alguns, inclusive, ririam de sua empresa como um "neoaristotelismo" que tentava renovar a ideia de uma hierarquia dos seres e a concepção teleológica de uma 
natureza que expressa fins ${ }^{1}$. E, de fato, após a publicação do livro inflacionaram-se as definições que o aproximaram de Aristóteles. Fala-se em "neo-aristotelismo"2, "quasearistotelismo", e até "cripto-aristotelismo", mas nada disso se torna muito claro quando se pergunta em que sentido pode Jonas ser aproximado de Aristóteles. Jonas observa, entretanto, o seguinte:

na realidade, Aristóteles não tinha sido tão importante no curso de minhas reflexões, mas não há que se ignorar que depois da publicação de meu liviro $O$ Princípio Responsabilidade alguns não tardaram em dizer: "em seu pensamento há um elemento aristotélico'. Seria anedótico acrescentar aqui que um dos primeirros a manifestar um reconhecimento pelo livro [...] foi Gadameir. Um dia me enviou uma longa carta que começava com as seguintes palaviras: 'Caro senhor Jonas, com a presente carta gostaria de me confessar como uim grato leitor de seu livro'. E em uma passagem apontava: 'graças a ele, ficou claro para mim que Aristóteles se torna sempre mais atual para nós ${ }^{5}$.

E Jonas ainda acrescenta que depois que Robert Spaemann, filósofo católico de fortes tendências aristotélicas, congratulou-lhe pelo livro, ele admitia ter pouco o que alegar contra a classificação de neoaristotelismo $0^{6}$. Para Jonas, tal classificação não era, de qualquer modo, uma depreciação, mas ele enfatiza que ela teve como consequência que "para os que se identificam com a Escola de Frankfurt" Jonas parecera um conservador, a tal ponto que Habermas impedira que Jonas obtivesse o Prêmio Adorno?.

Mas a despeito dessa atribuída aproximação com Aristóteles - e que para ele não era, de qualquer modo, uma depreciação -, em entrevista a Harvey Scodel, Jonas também diz:

um ensaio de Kant que me influenciou, impressionou, e determinou tremendamente: Grundlegung zur Metaphysik der Sitten teve uma influência quase determinante em minha vida porque fixou de una vez por todas a ideia, a secreta ideia que tenho de ética, de uma ética filosófica. Mais tarde essa impressão foi muito modificada pelo meu contato com Aristóteles. Mas essa inspiração Kantiana permaneceu de alguma forma comigo ${ }^{8}$.

${ }^{1}$ Cf. JONAS, Hans. Erinnerungere Nach Gesprăchen mit Rachel Salamander. Frankfurt am Main: Insel Verlag, 2003, p. 324.

${ }^{2}$ BERTI, Enrico. Il Neo-aristotelismo di Hans Jonas. Iride, $n^{\circ}$ 6, janvier-juin 1991, p. 227-231.

${ }^{3}$ APEL, K-O. Macroethics, Responsability for the future and the crisis of technological Society: reflections on Hans Jonas. In: Karl-Otto Apel selected essays. New Jersey: Humanities Press, 1996, p. 219-243.

${ }^{44}$ VOLPI, Franco. "Le Paradigme Perdu": l'éthique contemporaine face à la technique. HOTTOIS, G. (Éd.). Aux Foundaments de la Ethique: H. Jonas et H. T. Engelhardt. Paris: Vrin, 1992, p. 163-179.

${ }^{5}$ JONAS, Hans. Erinnerungen, op. Cit., p. 325. Na verdade, não se tratava de uma carta tão longa assim. Trata-se da carta, datada de 2.9.1980, que quando em Heidelberg-Ziegelhausen Gadamer escreve para Jonas, e cuja tradução segue abaixo: "Caro senhor Jonas, / Com a presente carta gostaria de me confessar como um grato leitor de seu 'Princípio [Responsabilidade]'. Há nele muito da boa e velha virtude fenomenológica. $\mathrm{O}$ alemăo me parece antigo, embora de modo algum antiquado, mas antes escrito de forma muito apropriada - algo que me impressionou bastante. Pois minha própria experiência me ensina que apesar de há muito estar aí e falando apenas em inglês, para mim escrever em alemăo nunca me deixou de ser próximo. (Ao escrever em inglês não consigo de modo algum pensar!). / O que mais me chamou a atenção foi o antigo tema kantiano do imperativo 'categórico' em sua relação com o imperativo da prudência [Klugheit]. Posso concordar com sua crítica a Max Weber. Mas me pego pensando algo sobre os seguintes pontos: não se torna Aristóteles sempre mais atual? Para ele a polis grega era o mundo. [O binômio] "homem e terra" não é para nós o mesmo que para ele era a polis! E consegues ver uma forma de ethos além do relativismo, pelo menos de forma aproximativa? / Estou em alguma medida no caminho certo? Agora, de qualquer forma obrigado, pois o senhor me deixa 'a caminho [merwegs]'. De seu, HGGadamer" (GADAMER, Hans-Georg. Hans-Georg Gadamer und Hans Jonas: Briefe über die Zukunftsethilk. In: Orientierung und Verantwortung. Begegnungen und Auseinandersetzungen mit Hans Jonas. Dietrich Böhler und Jens Peter Brune [Hrsg]. Würzburg: Königshausen und Neumann, 2004, S. 479482 [p. 479]). Trata-se da primeira e única publicação até agora desta correspondência, que hoje pode ser encontrada no Arquivo Hans Jonas em Konstanz.

${ }^{6}$ cf. JONAS, Hans, Erinnerungen, op. Cit., p. 325.

7 cf. JONAS, Hans. Erimnerungen, op. Cit.., p. 326

${ }^{8}$ JONAS, Hans. An Interview with Professor Hans Jonas (By Harvey Scodel). Social Research 70, $n^{\circ} 2$, Summer 2003, p. 339-68 [p. 343]. 
Como se pode notar, é com Kant que o autor de Das Prinzip Verantwortung formulou sua ideia de uma ética filosófica, e isto fica claro com uma boa dose de orientações: a importação do estilo categórico de expor o princípio responsabilidade, reclamando o caráter deontológico da ética é certamente o fator principal. Mais: Gadamer vê na fundamentação ontológica de Jonas uma elucidação do fato da liberdade em Kant. Diz ele:

Aí aparece certa divergência entre nós, que vejo como estando mais relacionada à argumentação fillosófica do que aos resultados e às conclusões. No fundo o senhor segue também Kant quando fala da dadidade «Gegebenheit $\rrbracket$ da responsabilidade: este é o fato da razão, a liberdade. O senhor busca, entretanto, uma fundamentação ontológica, e não sei se esta última é realmente independente daquele fato fundamental e não antes a mesma coisa explicitada tal como Kant o faz de forma convincente, também para nós hoje, na terceira formulação do Imperativo Categórico: "todo seir humano é uim fim em si". [ [...] Não me parece que sua forma de argumentação filosófica, sr. Jonas, se desvie essencialmente das implicações da "Metafísica moral" de Kant".

A teleologia da natureza e o homem como fim em si, comum a ambos, Kant e Jonas, confirmam essa leitura de Gadamer. Deixando de lado o sentimento de responsabilidade, que Jonas pensa em claro confronto com o sentimento de respeito em Kant, não se deve esquecer que, para Jonas, a filosofia também precisa ter, como já defendera Kant, uma função eminentemente prática. Ademais, é interessante notar também, além do âmbito ético, entre outras aproximações possíveis, que assim como em Kant a auto-responsabilidade, ou pessoalidade, é algo que transcende à mera racionalidade ou humanidade, também em Jonas a responsabilidade representa o nível de liberdade mais transcendente ${ }^{10}$. Ademais, como Eric Pommier ${ }^{11}$ bem percebeu, as três perguntas kantianas nas preleções sobre Lógica - e a centralidade da antropologia para a filosofia aí implícita -, bem como a transformação da metafísica a partir de seu caráter especulativo como consequência da aceitação da finitude humana também são traços que marcarão a filosofia de Jonas.

Mas além de todos esses elementos kantianos - e muitos outros que se pode encontrar fora do âmbito propriamente ético -, com Das Prinzip Verantwortung, Jonas demonstra ter seguido, ademais, bem de perto, deliberadamente ou casualmente, entre outras coisas, uma sabedoria prática específica de Kant, a saber: a necessidade de fazer da filosofia um instrumento profético. É isto que pretendo demonstrar neste estudo, 40 anos depois do livro vir a lume, o que me permitirá avaliar também, tendo em vista os seus resultados esperados, o quanto o profético vale para o filosofia. Quero realizar, portanto, uma espécie de avaliação retrospectiva da fortuna do livro - o que possibilitará de maneira secundária também uma nova aproximação da ética da responsabilidade com a filosofia da história e a reflexão moral de Kant.

\section{O profético na filosofia de Kant}

O tema do profético aparece de maneira bastante peculiar na construção kantiana filosofia da história da humanidade. No caso de uma história filosófica da humanidade três pontos parecem ser decisivos: o passado (origem e desenvolvimento), o presente (condição atual) e o futuro (destino/fim). E Kant deu seu veredito em relação aos três pontos referidos, construiindo uma narrativa assumida e deliberadamente

\footnotetext{
${ }^{9}$ GADAMER, Hans-Georg. (2004). Hans-Georg Gadamer und Hans Jonas..., op. Cit., p. 481.

${ }^{10}$ cf. JONAS, Hans. Matéria, espírito e criação. Trad. de Wendell E. S. Lopes. Petrópolis: Vozes, 2010, p. 31-32.

${ }^{11}$ POMMIER, Eric. (2015). Life and Anthropology: A Discussion between Kantian Criticism and Jonasian Ontology. Giornale Critico di Storia delle Idee, n. 14, 2015, p. 123-136 [ip. 123].
} 
especulativa, indo de um "início conjectural"12 até a elaboração do que ele próprio chamara de uma "história profética da humanidade" ${ }^{13}$. Aqui nos importa exatamente a dimensão do futuro, pois enquanto o primeiro permite pensar de onde a humanidade se desgarra da natureza, é o segundo que oferece a oportunidade para a análise da dinâmica da história humana e seu destino futuro.

Kant adota a atitude de ver o destino/fim humano desde a perspectiva da evolução moral, e isto quer dizer, ele acredita que há um movimento do pior para o melhor ${ }^{14}$, e mesmo um "progresso em direção à perfeição"15. Mas onde se alicerça essa fé filosófica de Kant? Ao que parece, tal como se pode encontrar em "Ideia de uma história universal em perspectiva cosmopolita" (1784) e na Segunda Seção de O conflito das faculdades (1798), o filósofo ataca o problema da dinâmica histórica a partír do recurso a um princípio teleológico da natureza em associação com um procedimento dialético de base. Seguirei a argumentação de Kant no segundo texto referido, porque nele o filósofo volta ao problema, oferencendo uma modificação de sua aproximação ao problema da dinâmica lhistórica a partir dos estrondosos eventos da Revolução Francesa.

Nesse texto intitulado "Reiteração da pergunta sobre se o gênero humano se acha em constante progresso até o melhor" somos apresentados ao que Kant chama de "história prenunciadora", adivinhatória (pois especulativa e não baseada em leis naturais) e ao mesmo tempo "profética"16. Esta narrativa profética da história do porvir, que se refere à "história moral" e não à "história natural", se mostra como uma "exposição possível a priori dos acontecimentos", uma verdadeira "história a priori"17. Como ela é possível? A resposta de Kant é: quando "o próprio profeta faz e dispõe os acontecimentos que anuncia de antemão"18. Em seu famoso ensaio "Ideia de uma história universal em perspectiva cosmopolita", Kant já defendera que o filósofo também pode e deve agir como um profeta, pois diz ele: "um ensaio filosófico que procure elaborar a história geral do mundo segundo um plano da natureza, em vista da perfeita associação civil no gênero humano, deve considerar-se não só como possível, mas também como fomentando esse propósito da natureza"19.

Mas quais possibilidades podem ser, segundo Kant, previstas/prenunciadlas acerca do porvir humano? Desde uma reflexão dialética, Kant considera três alternativas: a primeira delas seria a propugnada pelo terrorismo moral, que acredita no retrocesso constante, o que para Kant não é possível porque em algum momento isto significaria a auto-aniquilação. A deterioração tende a resultar numa renovação. Uma segunda alternativa, a do eudemonismo ou quiliasmo, sugere que a história humana "avança constantemente, em relação a seu destino moral, até o melhor" ${ }^{\text {"20 }}$. E a terceira alternativa para o problema da dinâmica histórica é a do abderitismo, segundo a qual a história oscila num processo cíclico entre avanços e retrocessos igualmente profundos. Para Kant, esta alternativa parece ser a mais "realista" entre as três analisadas, porque, de fato, a sina humana parece se assemelhar com a antiga história de Sísifo. Não obstante, por sua parte, o filósofo seguirá uma quarta alternativa, síntese das duas últimas alternativas referidas.

Mas Kant sabe que, do ponto de vista epistemológico, a decisão acerca da possibilidade do progresso histórico não pode se resolver pela experiência, mas deve ainda assim contar com acontecimentos que revelem pelo menos tendências de tal progresso. Naturalmente, nada garante que isto continue acontecendo sem o início de um retrocesso. Se a vontade humana, apesar de limitada, fosse inata e invariavelmente

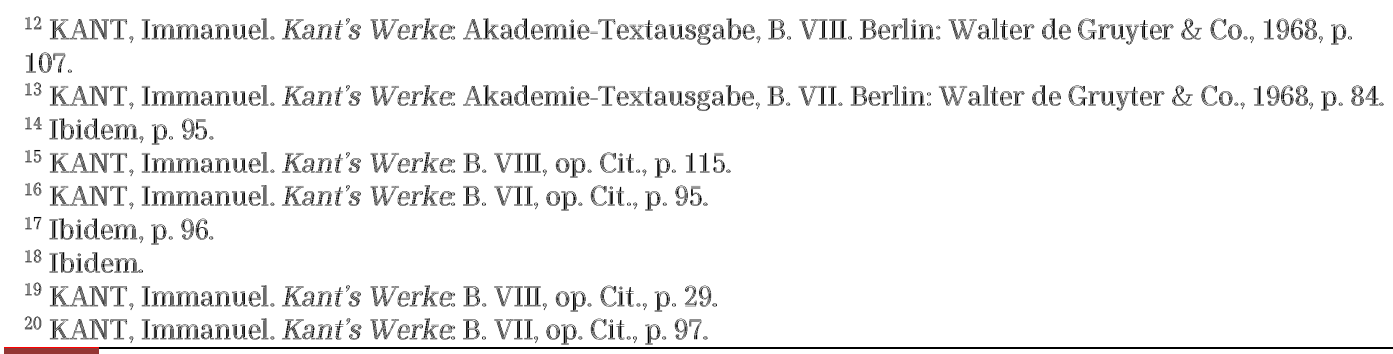


boa, poderíamos prever o desenvolvimento moral, mas este não é o caso, pois bem e mal se mesclam na natureza humana, de modo que não sabemos que efeitos podemos esperar. Mas apesar disso Kant acredita que, de fato, a história profética pode se vincular a alguma experiência, já que há um acontecimento que nos permite "inferir a progressão para o melhor, como consequência inelutável", embora tal acontecimento não deva ser visto como uma causa, "mas somente como indicativo, como sinal histórico (signum rememorativum, demonstrativum, prognosticon)", podendo, por isso, "demonstrar a tendência do gênero humano, olhada no seu todo"21 . E o critério que Kant exige para esse acontecimento é a pura demonstração de ser uma intervenção moral dupla, a do direito, garantindo uma constituição civil, e "um fim (que ao mesmo tempo é dever): a constituição de um povo que será conforme ao direito e em si mesma boa" caso seja capaz de evitar a guerra, que é, para Kant, "a fonte de todo mal e de toda corrupção dos costumes" 22. Este é o caso de uma constituição republicana ${ }^{23}$. Com ela Kant vê um indicativo de asseguramento do progresso humano em direção ao melhor ${ }^{24}$.

$\mathrm{E}$, para Kant, uma vez alcançado esse fim de uma constituição republicana o gênero lhumano não retrocederia completamente, pois em sua percepção quando um fenômeno desse tipo acontece na história humana, não se lhe pode mais esquecer porque ele como que descobre uma disposição da natureza humana. Mais: mesmo que esse fim não fosse alcançado agora ou mesmo que, alcançado, se venha a perdê-lo, "aquela profecia filosófica não perderia nada de sua força" ${ }^{m 2}$, pois sua envergadura ficará marcada na história servindo de exemplo para novas repetições. E em algum momento ganhará firmeza suficiente para permanecer. O que é decisivo para Kant é uma constituição em harmonia com o direito natural, isto é, uma constituição em que os legislados se percebam também como legisladores. Enquanto pensada por conceitos puros da razão, tal constituição republicana é "um ideal platônico (respublica noumenon) [...] eterna norma de qualquer constituição civil em geral e do afastamento de toda guerra"26, e, enquanto uma sociedade civil que se organiza com base nela, é uma exemplificação dela segundo leis da liberdade, sendo, pois, a respublica phaenomenon.

A realização dessa constituição é, pois, um dever. Mas, claro, isto não se dá de forma repentina, por isso provisoriamente se realiza primeiro através de um monarca que governa republicanamente (não democraticamente), isto é, tratando seus súditos segundo princípios adequados à lei da liberdade - embora sem seu consentimento. Mas Kant observa: que "para a omnipotência da natureza, ou antes, da Causa suprema a nós inacessível", o homem seja "apenas uma pequenez"27, já que, segundo o filósofo, "poderse-ia imaginar que em outro planeta poderia haver criaturas em grau superior ao do homem"28, isto não significa, entretanto, que "os soberanos da sua própria espécie assim o considerem e como tal o tratem", já que se configuraria como uma inversão do fim último da criação"29. Portanto, que do ponto de vista da natureza, a humanidade não seja necessariamente um fim em si, da perspectiva do agente humano, ela o seria, porque o último na linha de produção ganha o direito de por-se como fim em sỉ, já que não inferior aos membros de sua própria espécie.

\title{
Jonas e o valor da profecia
}

\author{
${ }^{21}$ Ibidem, p. 101. \\ ${ }^{22}$ Tbidem, p. 103. \\ ${ }^{23}$ Tbidem, p. 105 \\ ${ }^{24}$ Tbidem, p. 103. \\ ${ }^{25}$ Tbidem, p. 105. \\ ${ }^{26}$ Ibidem, p. 108. \\ ${ }^{27}$ Tbidem, p. 106. \\ ${ }^{28}$ KANT, Immanuel. Kant's Werke: B. VIII, op. Cit., p. 95. \\ ${ }^{29}$ KANT, Immanuel. Kant's Werke: B. VII, op. Cit., p. 106.
}


O valor da profecia em Kant pode ter passado despercebido por muitos filósofos da tradição, mas, ao que parece, não por Jonas. A influência de Kant sobre ele é decisiva também a esse respeito, como se pode observar pela seguinte declaração:

Inspirado pelo meu especial interesse em Judaísmo, ainda durante meus tempos ginasiais comecei a ler os profetas de Israel [do Antigo Testamento], através da tradução comentada pelos membros da escola protestante de história da religião e de crítica textual - um fruto da ciência contemporânea. [...] minha experiência com os primeiros rebentos da ciência no domínio da religião foi conhecer os profetas em seu tempo e mundo, já que de simples personagens homiléticos dos textos sagrados ela os transformou em figuras de carne e osso, tornando-os inais vivos para nós, mais próximos do nosso presente, não afastados deste, sem deixar de manter o seu próprio poder natural - de que eles poderiam de algum modo existir. [...] E minha primeira leitura filosófica naqueles dias acabou sendo, não sei por que acidente, a obra Fundamentação da Metafísica dos Costumes, de Kant, na qual acreditei ter redescoberto o ethos dos profetas, embora, dessa vez, como uima douitrina da razão, permitindo-me entrever que existem pontos de contatos entre a filosofia e a religiã $0^{30}$.

Como judeu, Jonas sempre carregou consigo o valor da tradição dos profetas. A primeira coisa a notar é que Jonas é um filósofo judeu-alemão. O significado dessas palavras é mais forte que a mera caracterização biográfico-profissional de enciclopédia. Ele aponta antes para um aspecto existencial importante do pensar de Jonas enquanto filósofo. Para assimilarmos primeiro o peso da tradição judaica sobre o filósofo, precisamos entender que a contragosto de seu pai, que àquela época ainda acreditava com grande esperança na assimilação dos judeus à sociedade alemã, o jovem Jonas, aos 17 anos, mostrava já grande suspeita a respeito da possibilidade de assimilação dos judeus na Alemanha e passara a frequentar reuniões do movimento sionista, que militava em favor de um Estado judeu independente. O engajamento ultrapassou a esfera da mera militância e alcançou também tremendo dispêndio intelectual: como sionista engajado, Jonas publicou, ainda jovem, seus primeiros ensaios - todos de forte teor judaico. No volume recém-publicado da Kritische Gesamtausgabe das obras de Jonas, que traz o título muito sugestivo de Herausforderungen und Profile. Jüdischdeutscher Geist in der Zeit - gegen die Zeit [Desafios e perfis. O espírito judeu-alemão no tempo - contra o tempo] (2013), os editores resgataram, na primeira parte, praticamente todos os textos de Jonas em que o espírito judaico aparece representado ${ }^{31}$. São exemplares para nosso propósito atual os textos de juventude intitulados "Die Idee der Zerstreutung und Wiedersammlung bei den Propheten" [A ideia de dispersão e reagregação nos profetas] (1922), "Das jüudische Schulwesen in Palästina" [O sistema educativo judaico na Palestina] (1923) e "Die jüdische Missionsidee" [A ideia de missão judaica] (1926), que não passou de fato do esboço de um escrito para seminário (Referatsskizze). Pelos meros títulos desses ensaios, não é difícil entender que os estudos de filosofia não podiam ter sido levados a cabo sem um estudo de religião comparada. Que entre os períodos de 1921, em que estuda em Freiburg (com Husserl e Heidegger), e 1924, sob os auspícios do Heidegger de Marburg, Jonas suba até Berlim, não teve outra motivação senão a necessidade de seguir adiante com tais estudos judaicos. Dessa época de estudos na Universidade de Berlim se conservou o esboço de uma carta quase

\footnotetext{
${ }^{30}$ JONAS, Hans. Wissenchaft als Persönliches Erlebnis. Göttingen: Vandenhoeck \& Ruprecht, 1987, p. 12-13.

${ }^{31}$ Uma contribuição desse volume é ter desenterrado textos publicados por Jonas (e alguns não publicados), mas esquecidos ou mesmo desconhecidos dos comentadores e intérpretes, oferecendo inclusive uma visão de seus primeiros trabalhos. Böhler explicita que "O subtítulo deste volume é justificado principalmente pelo auto-entendimento filosófico-judaico, expresso em numerosas contribuições. O desafio nele contido, não apenas de incorporar e representar subjetivamente a exposta auto-compreensão ético-religiosa e o amplo compromisso ético social, de fato a missão moral do judaísmo, mas de provar que as demandas morais e imposições normativas decorrentes dela podem ser generalizadas, já causou estranheza aos jovens alunos" (BÖHLER, Dietrich. Einleitender Kommentar. In: Kritische Gesamtausgabe der Werke von Hans Jonas, B. III/2. Freiburg i. Br./Berlin/Wien: Rombach, 2013, p. xvii-Xxxix [p. XIX]).
} 
completamente elaborada, escrito por Jonas, para seu antigo professor Eduard Spranger, em 1922, no qual o jovem Jonas confessa o real significado de seu engajamento judaico nos tempos em que era estudante: "sinto algo do espírito e da vocação dos profetas veterotestamentários em mim ${ }^{\prime \prime 32}$. Essa é uma forte confissão - e posterior ao contato com - Lehrerwirkung de Heidegger, que Jonas conhecera já em 1921. Essa vocação transparece também, ademais, na famosa passagem do Pregador, "lança seu pão sobre as águas" (Ecl 11,1), da qual Leon Kass recorda ter ouvido de Jonas ${ }^{33}$, que por sua própria parte não deixou de expressá-la, criticamente contra Arendt, no final de seu ensaio festivo sobre o que, para ele, era a obra filosófica de sua velha amiga ${ }^{34}$. Não é mero destino fortuito que, com a ascensão de Hitler, Jonas se lance em exílio até chegar à Palestina, lutando contra o nazismo na segunda guerra mundial e retomando a Jerusalém, de onde só saiu em função das dificuldades pessoais e financeiras que encontrou e não conseguiu vencer ${ }^{35}$.

Um trabalho laborioso e de grande competência a respeito do elemento judaico no pensamento de Jonas foi feito por Christian Wiese em seu livro The Life and Thought of Hans Jonas: jewish dimensions (2007), em que o autor defende a tese de que "não se pode ignorar a 'dimensão' judaica sem perder uma parcela significativa da própria experiência biográfica e das intenções filosóficas de Jonas"36. Tudo isso, entretanto, não significa que se deva alinhar o propósito de Jonas a uma filosofia judaica. É preciso saber equacionar a herança judaica e a argumentação filosófica no pensamento jonasiano. Sua filosofia é laica e marcada por uma espécie de ateísmo metodológico ${ }^{37}$. Esse forte background judaico, portanto, não pode fazer o estudioso perder de vista, entretanto, que, mesmo se há uma espécie de autocompreensão judaico-filosófica, é a filosofia que molda o elemento judaico e não o contrário. A esse respeito, deve-se entender que a autocompreensão judaico-filosófica não se assenta apenas na linha moral, isto é, não é meramente autocompreensão ético-religiosa, que agrega o compromisso social-ético e a missão moral do judaísmo, mas integra e estabelece de maneira livre e independente (não ortodoxa) principalmente a relação de uma fé particular com o modus operandi racional e universalista da filosofia. Na fórmula precisa de Alan Rubenstein, sua religiosidade "enfatizou os elementos universais poder-se-ia dizer filosóficos - da herança judaica"38. Na resolução de uma vida entre os profetas e os filósofos, portanto, Jonas, muito além da "vocação profética" que víamos

\footnotetext{
${ }^{2}$ JONAS, Hans. Kritische Gesamtausgabe der Werke von Hans Jonas, B. III/2. Freiburg i. Br./Berlin/Wien: Rombach, 2013, p. 173.

${ }^{33}$ KASS, Leon. (2001). Appreciating the Phenomenon of Life. Graduate Faculty Philosophy Joumal, v. 23, n. 1, 2001, p. 51-69 [p. 52]。

${ }_{34}$ JONAS, Hans. Acting, Knowing, Thinking: Gleanings from Hannah Arendt's philosophical work. Social Research, $\mathrm{v}_{.} 44, \mathrm{n}^{\circ} 1,1977$, p. $25-43$ [p. 42-43].

${ }^{35}$ A respeito do papel de Jonas na guerra até a constituiçăo do Estado de Israel, o testemunho mais eloquente é o discurso "Unsere Teilnahme an diesem Kriege: Ein Wort an jüdische Mănner" [Nossa parte nesta guerra: uma palavra aos homens judeus], de 6 de outubro de 1939 (cf. JONAS, Kritische Gesamtausgabe der Werke von Hans Jonas, B. III/2. Op. Cit., p. 61-76).

${ }^{36}$ WIESE, Christian. The life and thought of Hans Jonas: Jewish dimensions. Trad. Christian Wiese and Jeffrey Grossman. Hanover/London: University Press of New England, 2007, p. xxiii.

${ }^{37}$ É o que se pode extrair da entrevista de Jonas concedida a Herlinde Koelbl: "O filósofo precisa levar a cabo seu próprio negócio, o pensar, de maneira totalmente livre de vínculos e pré-conceitos herdados. Ele está comprometido apenas com o pensar. A filosofia precisa ser 'ateística' no método. Isto não significa afirmar dogmaticamente que 'Deus não existe'. Mas significa não permitir dizer nada desde a perspectiva de uma fé [religiosa]. Que se possa ser ao mesmo tempo filósofo e judeu - eis uma certa tensão da qual não há que se duvidar" (JONAS, Kritische Gesamtausgabe der Werke von Hans Jonas, B. III/2 Op. Cit., p. 156). Mas é importante salientar que o "ateísmo do método", entretanto, observa ele, "não resultou no ateísmo como ponto de vista nem em um agnosticismo completamente neutro, mas antes em uma metafísica com uma conjectura teística" (ibidem, p. 156). E, se aqui a suspeita da herança judaica não pode ser completamente abandonada, também o não religioso, pensa Jonas, não pode se considerar isento de pré-conceitos que orientam sua resposta à questã̃o.

${ }^{38}$ RUBENSTEIN, Alain. Judaism and nature: Reviewing the Jewish Dimensions of Hians Jonas. Religious Studies Review, vol. 36, n. 1, 2010, p. 15-21 [p. 16]。
} 
despontar no período de juventude, não deixa de enfatizar, por fim, a "reflexão filosófica" como "vocação escolhida"39.

Essa passagem por considerações contextuais histórico-biográficas tỉnha como objetivo mostrar a relação estreita do jovem Jonas com o ethos dos profetas. Mas o fato é que algo dessa vocação profética pode ser detectado ainda no período de maturidade do filósofo, quando o Jonas eticista não se abstém da profecia do pior como poder filosófico de reorientação da realidade histórica. O valor do profético aqui fica claramente tematizado no ensaio "No limiar do futuro: valores de ontem e valores para amanhă"40, texto em que Jonas reflete sobre uma visada até o futuro e sua possível aparência. Tal visada precisa ter em mente que é certo que as energias universais que mobilizamos hoje constituem o rosto do futuro - e isto é verdade hoje mais do que em qualquer outra época, pois em nossa época "tudo tende até mais adiante" civilização que vive sob o signo do progresso. Mas é certo também que, mesmo que sejamos capazes de fazer convincentes antecipações (Vorblicke) do que o futuro reserva para a humanidade, tais antecipações só podem ser hipotéticas, uma vez que a cláusulla rebus sic stantibus não se aplica à hisistória de maneira tão satisfatória como acontece com a ciência física, que conta com a uniformidade das leis naturais. Assim, "o inesperado é aqui a regra, e a surpresa, aquilo que se deve esperar ${ }^{542}$.

E não se trata de dizer que tal antecipação hipotética seja possível, mas antes que ela é mesmo um novo valor que nos arranca do fatalismo. Nesse sentido, "através da retroalimentação do sujeito teórico ao prático, a própria previsão [Vorhersage] se torna um fator de seu cumprimento ou refutação"43. Pois o próprio evitar a previsão depende da ação humana. Aqui não há lugar para uma necessidade universal da história ao estilo de Hegel, Marx, Comte e Spengler. Jonas diz mesmo que a figura do profeta só pode se realizar se este se coloca como mero agente contemplativo e mesmo esconde sua profecia histórica de outros sujeitos históricos, objetos da própria profecia; pois a predição pode mobilizar os próprios objetos da profecia a agirem em contraposição ao próprio destino que lhes foi previsto. O resultado disso é até certo ponto paradoxal: o acerto profético não significa exatamente acerto, mas antes quer dizer que nada se fez em relação à profecia; por outro lado, o fracasso da profecia não significa de modo algum fracasso caso os agentes históricos tenham agido no sentido de impedir a própria realização da profecia. Essa observação jonasiana é importantíssima: o pensar distópico pode contribuir para uma nova forma de assimilação tecnológica, o que quer dizer que não há fatalismo na profecia do pior, antes ela serve muito bem como uma mobilizadora das energias universais do homem em relação a si mesmo. Com tudo isto observado, Jonas chama seus "profetas" de "preditores hipotéticos" (hypothetischen Vorhersagern), uma vez que só falam do que pode acontecer, nunca do que necessariamente irá acontecer. Eles inclusive profetizam para ter como resultado não o ter razão, mas o equivocar-se. Assim, tendo em vista as possibilidades extremas do poder humano, "a projeção do futuro a longo prazo, de maneira hipotética, fundada cientificamente e o mais global possível (o que não é menos certa por ser hipotética) talvez seja o primeiro novo valor a se exercitar hoje para o mundo de amanhã $\tilde{a n}^{\prime 4}$.

E há que se observar, por fim, que a vocação do profeta, de um lado, não pode ser realizada caso, de outro, não exista o chamado para a sua atuação. A profetização não é uma atitude meramente deliberada, mas é a resposta a um chamado. Neste caso, o

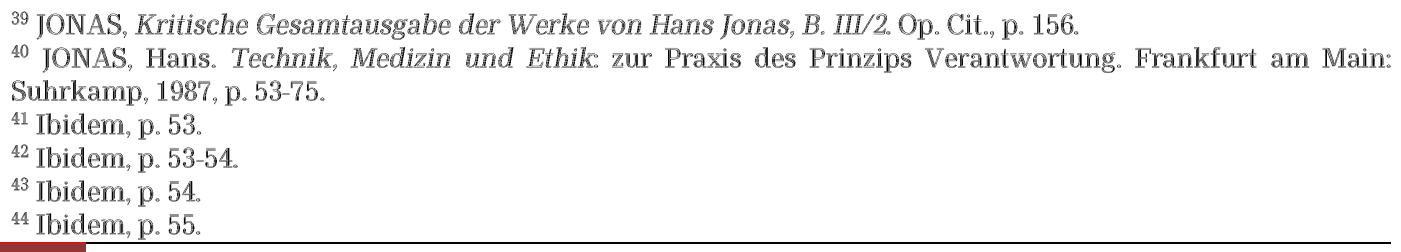


chamado não é de tịpo religioso, mas pode ser alinhado com o que Jonas chama de "o clamor das coisas mudas" $"$.

\section{O recurso a uma Heurística do temor}

Mas por que o recurso ao profético? E como ele opera na reflexão ética de Jonas? O profético aparece no livro Das Prinzip Verantwortung com o nome de "heurística do temor". Qual o papel dessa heurística do temor? O que se deve entender é que em matéria de ética, Jonas sempre se perguntou a respeito de quais são as chances de se conseguir controlar o progresso de modo que "os resultados de quaisquer ideias [insights] éticas (ou até puramente prudenciais) possam ser traduzidas em ação efetiva? Como a liberdade humana pode prevalecer sobre o determinismo [tecnológico] que ela criou para si mesma"46. Da possibilidade de resposta a essa questão depende a efetividade ou futilidade da investigação ética.

Pensa-se às vezes que o poder tecnológico ampliou a liberdade humana, pois abriu uma série de oportunidades de escollha antes inviáveis do ponto de vista econômico. Mas Jonas pensa que estamos diante de uma mudança que foi de um "determinismo homogêneo" para um "determinismo multifatorial" exercido pelo artefato humano sobre o seu criador e usuário. Aqui não se pode deixar levar pelas palavras: o homem (este "nós" abstrato) certamente se tornou mais poderoso, mais aos homens individuais aconteceu o oposto, já que se tornou cada vez mais dependente. De um lado, você tem um complexo tecnológico impessoal" com seu dinamismo quase automático, de outro, se tem a "patologia do cliente que é a sociedade". Desse modo, Jonas pensa que a tirania do destino se tornou maior, e por isso mesmo menor a capacidade de tomada de decisões. O imperativo da responsabilidade, que reza: "age de tal modo que sua ação seja compatível com a existência digna da humanidade no futuro" ${ }^{\prime 47}$, tem como intençăo fazer frente ao perigo técnico e a consequente patologia societária.

É certo que existem muitas dificuldades para tal imperativo. Uma delas se deve à própria ingenuidade das pessoas em relação à tecnologia e ao progresso, isto é, à consideração exclusiva de seus benefícios. Mas apesar disso, é preciso não se deixar levar pela utopia e fazer valer tal imperativo ético; é preciso pensar uma nova forma de utilização do poder técnico e enfrentar o seu avanço e progresso. O problema aqui se torna a possibilidade de efetivação de uma responsabilidade a longo prazo, o que levanta a questão também da liberdade (democrática). Ainda que as antigas virtudes tenham validade na esfera pessoal, a coisa muda quando se trata da esfera coletiva: aqui se revela a necessidade de sanções - embora se possa renovar a consideração de certas virtudes, como Jonas faz com o caso da antiga virtude medieval da frugalidade, como uma orientação contra a atual glutonaria da sociedade de consumo.

É face à dificuldade de efetivação da responsabilidade pelo futuro que, para Jonas, faz-se necessário uma heurística do temor como norte da ação política. Ela nada mais é do que a expressão do uso da profecia como ferramenta para a concretização de ideias éticas em ação efetiva. A heurística do temor é um procedimento que tem a função de antecipar o temível para assim mobilizar o sentimento de responsabilidade e a consequente salvaguarda do nosso ser. Jonas sabe que o sentimento desperta mais os homens do que razões. Essa heurística do temor - que dá ao princípio de responsabilidade o caráter de um verdadeiro princípio de precaução - sugere que em face do real desconhecimento dos efeitos da ação tecnológica, devemos considerar os maus prognósticos antes que os bons. Nathalie Frogneux percebeu algo desse elemento

${ }^{45}$ JONAS, Hans. The Outery of Mute Things (January 1993) In: Mortality and Morality: a search for good after Auschwitz. Ed. Lawrence Vogel. Evanston, Illinois: Northwestem University Press, 1996, p. 198-202.

${ }^{46}$ JONAS, Hans. Toward a philosophy of technology. In: SCHARFF, Robert C. \& DUSEK, Val (Ed.). Philosophy of technology. the technological condition: an anthology. Malden: Blackwell Publishing, 2004, p. 191-204 [p. 201].

${ }^{47}$ JONAS, Hans. Warum wir heute eine Ethik der Selbstbeschränkung brauchen" (In: STRÖCKER, Elisabeth (Hrsg.). Ethik der Wissenschaften? Philosophische Fragen. Munchen - Paderbom, W. Fink-F. Schöningh, 1984, p. $75-86$ [p. 83]. 
profético da heurística do temor quando enfatiza o paradoxo de Cassandra no pensamento de Jonas. Diz a comentadora belga:

ele [Jonas] aceita o paradoxo do profeta cuja profecia é necessariamente falsa. Sua heurística do medo o leva, assim, a profetizar o pior com o objetivo de evitálo. A partir daí, de duas uima: ou a profecia como ato performático causa seu efeito e a catástrofe é evitada invalidando a profecia, ou a profecia fracassa enquanto aviso, não produzindo nenhuim efeito e se tornando verdade. [...] Na versão positiva, a predição ou profecia auto-realizadora (self-fulfeeling prophecy) anuincia uim estado futuiro do mundo cuija realização ela provoca [...] na sua versão negativa, ela se transforma num ato performático que tenta provocar o contrário daquilo que anuncia. Neste segundo sentido, que é o de Cassandira ou do profeta Jonas ${ }^{48}$.

O fato da ética da responsabilidade ter terminado como uma crítica da utopia (marxista em especial) não é sem motivos: como afirma Jonas "a crítica da utopia é implicitamente uma crítica da tecnologia em antecipação de suas possibilidades extremas $^{n+49}$. Tratava-se de pensar uma ética capaz de segurar as rédeas do progresso galopante em função do temor pela condição humana em face do quadro pintado pelo sonho tecnológico realizado - extremamente ameaçador, tratava-se, portanto, de uma "precaução inteligente". Diz Jonas: "quando o princípio esperança não é mais a inspiração, então, talvez, é a advertência do temor que pode nos conduzir à razão" ${ }^{\text {"50 }}$. Como bem explicitou Dietrich Böhler, a análise de Jonas sobre a situação atual não só é irrefutável, mas ela nos desperta para o fato de que a sociedade tem tratado o diagnóstico com certo eufemismo, pois vivemos não apenas numa época de "crise ecológica", mas antes numa nova era de "risco permanente". Em suma, diz ele com Jonas: "nos encontramos em uma civilização de risco e em uma sociedade que põe em risco o futuro" 51 . Ter-nos aberto os ollhos para o caráter ameaçador da tecnologia foi obra daquele estilo de literatura que ficou conhecida como "utopia negativa" ou "distopia", como é o caso do Brave New World de Aldous Huxley. isto é, a uma ação autodisciplinada e moderada. É este diagnóstico que nos obriga a deixar de lado, pelo menos momentaneamente, a "ética da perfectibilidade" em atenção a uma ética mais austera, aquela da responsabilidade pelo futuro - uma ética da prevenção. Como diz Jonas, "o tempo para a imprudente corrida do progresso acabou" ${ }^{\circ / 52}$, ou se se preferir, como ouvi uma vez: the human race is no race at all.

\section{Os ganhos da profecia jonasiana}

Mas o que dizer dos efeitos da profecia expressa nos termos da heurística do temor? Tratou-se de uma profecia que demolia qualquer tipo de esperança ao prever a catástrofe? Ou, de outro modo, aqui se pergunta sobre o que a profecia jonasiana conseguiu de resultado, se é que algum? Há que se dizer antes de tudo que apesar do abandono da esperança utópica há abertura para uma nova esperança na ética da responsabilidade enquanto ética da auto-limitação e da prevenção. Jonas foi um eticista sóbrio. Ele sabia das dificuldades que a humanidade teria pela frente; sabia também que a palavra dos admoestadores é ignorada. Mas como um novo moscardo agitador, ao assumir a responsabilidade do filósofo, ele não se deixou levar pelo desafio da

${ }^{48}$ FROGNEUX, Nathalie. (2007). O Medo como Virtude de Substituição. In: NOVAES, Adauto (Org.). Ensaios sobre o medo. São Paulo: Ed. SENAC São Paulo: Ediç̃es SESC SP, 2007, p. 187-207 [p. 200].

49 JONAS, Hans. The Imperative of Responsibility. in search of an ethics for the technological age. Chicago: The University of Chicago Press, 1984, p. 201.

${ }^{50}$ JONAS, Hans. Dem bösen Ende năher. Gespräche über das Verhältnis des Menschen zur Natur/ Hrsg. Wolfgang Schneider. Frankfurt am Main: Suhrkamp, 1993, p. 91 [grifos meus].

${ }^{51}$ BÖHLER, Dietrich. (2003). Em la duda a favor de la responsabilidad y de la vida. A la memória de Hans Jonas (1903-1993). Paradoxa, 10, Octubre, 2003, p. 13-65 [p. 17].

52 JONAS, The Imperative of Responsibility, op. Cit., p. 201. 
complacência e da apatia, e de forma vigorosa sustentou em Berlin, perante os olhos de uma geração de estudantes, a necessidade de que sociedade e os pensadores, em especial, não se entregassem ao fatalismo: contra Heidegger, mas talvez também contra Gadamer $^{53}$, diz ele, "o fatalismo seria um pecado mortal" " Com essa afirmação presenciamos o encontro do princípio responsabilidade com o princípio esperança. A esperança da responsabilidade, que diante de sua enorme e permanente tarefa não se degenera à tentação de seu "pecado mortal", não se confunde, entretanto, com a esperança utópica no melhor dos mundos nem com qualquer sonho de perfeição, mas antes se estabelece como esperança pela possibilidade de um futuro ainda humano para as gerações vindouras. $\mathbb{E}$, de fato, o não-desesperar jonasiano ainda persistente não é uma mera esperança vã. Antes de tudo, ele pensava que muito antes da esperança em uma boa vontade, o choque diante das catástrofes, e o temor que lhe é próprio, poderia cumprir o elemento psicológico necessário para uma mudança de atitude. De qualquer forma, "em última análise", diz Jonas, "minha esperança está depositada na razão humana - a mesma que na conquista de nosso poder se mostrou tão estupenda e que agora deve encarregar-se de sua direção e limitação. Desesperar dela seria irresponsável e uma traiç̧ão a nós mesmos s"55.

E embora Jonas se preocupava com a pouca efetividade que talvez sua empresa ética pudesse ter quando da escrita de Das Prinzip Verantwortung, ele mesmo viu crescer sua esperança em muitos tipos de atividades que desde seu esse livro floresceram nos quatro cantos do globo. Antes de tudo não se pode esquecer da repercussão do próprio Das Prinzip Verantwortung. É certo que tal sucesso dependeu em boa medida de um clima de conscientização favorável, mas o próprio impacto do livro em um solo favorável deu ainda mais força ao estabelecimento do que veio a ficar conhecido como "consciência ecológica" - e Jonas é conhecido na Alemanha como o "filósofo da consciência ecológica"

Além disso, a esperança de Jonas pode encontrar um belo amparo mesmo onde ele menos podia esperar, lá onde a sabedoria e a limitação da liberdade pelo Estado se unem para a tarefa da responsabilidade, e permitem mostrar que mesmo o reaparecimento do rei-filósofo não pode ser lido senão como o próprio Jonas o chamara, como uma renovação do problema. Esta renovação fica clara na entrevista concedida a Christian Schütze, na qual ao saber que o governo alemão institucionalizou a prática dos conselheiros científicos em matéria de política ambiental (que por lá é composto por homens de ciência e sociólogos eminentes), Jonas declara: "eis uma versão temperada da ideia platônica. Ninguém defenderá hoje a ideia de tornar os filósofos em governantes,

\footnotetext{
${ }^{53}$ Para entendermos a posiçăo jonasiana, não faz mal se a compararmos com a pouca esperança que seu amigo de longa data, Gadamer, demonstrara-lhe em carta: "Que o senhor aceite por fim até mesmo a tirania, caso se precise perder as esperanças com o "laissez aller" da democracia - e isto já é quase necessário - presto-lhe honra, mas me parece inaceitável. O que um tirano pode fazer com os meios de poder de hoje (os quais ultrapassam infinitamente àqueles de que dispunha Hitler), parece-me impensável, tal como permanece impensável o eritis sicut Deus de Hitler. / Mas infelizmente o senhor tem razão quanto ao fato de que não podemos esperar sucesso algum com a auto-limitação salientada pelo senhor, especialmente por parte dos "responsáveis' - isto precisaria ser, inclusive, acordado por todos os 'responsáveis'. Assim permanece a afirmação fatal de Tugendhat: "antes vermelho do que morto"... Que o mundo não irá de repente começar a ouvir os professores, eis algo irrelevante para Tugendhat - mas infelizmente também o é para nós mesmos. Quero dizer com isso que no que concerne ao campo dos imperativos técnicos não temos o que fazer e assim permaneceremos. / Eu poderia acrescentar, ao estilo da crítica aristotélica a Platão na "Política", um grande número de sábias considerações [Klugheitserwägungen] às suas conclusões e creio ainda que nas mãos das pessoas a futurologia não se encontra em boas mãos [....] Também creio que o temor [Furcht] poderia mais prontamente - em função de um esgotamento próximo - ser escutado. Mas do fundo do illuminismo [Aufklärung], permanece difícil evitar o fim da humanidade - independente de quando quer que seja" (GADAMER, Hans-Georg. Hans-Georg Gadamer und Hans Jonas, op. Cit., p. 482 [o último grifo é meu]).

54 JONAS, Hans. Fatalismus wäre Todsủnde. In: BÖHLER, Dietrich. und NEUBERTH, Rudi (Hrsg.). Herausforderung Zunkunftsverantwortung: Hans Jonas zu Ehren. Muunster: Lit, 1993, p. 49-51 [p. 49].

${ }^{55}$ JONAS, Hans. Wissenchaft als Persönliches Erlebnis, op. Cit., p. 45.

${ }^{56}$ Para um maior detalhamento da repercussão do impacto político da obra de Jonas, cf. SCHÜTZE, Ch. (1995). The Political and Intellectual Influence of Hans Jonas. The Hastings Center Report, V. 25, $n^{\circ}$ 7, p. 40-44, 1995.
} 
mas seria preciso talvez consultá-los - apenas caso se tratasse de uma melhor filosofia"57. Para ele, isto é autorizado pela própria forma como a filosofia se encontra organizada nos tempos de hoje, isto é, com a presença de professores profissionais nas universidades. E nesse sentido Jonas salienta ser favorável a "uma função consultora da filosofia [philosophische Beratungfunktion] assegurada constitucionalmente, caso a filosofia fosse o que deveria ser. Como ela não o é, meu desejo é irrealista" (JONAS, 1993c, p. 42$)^{58}$

Um último aspecto do desenvolvimento de uma consciência própria da responsabilidade pelo futuro Jonas viu nas convenções internacionais, que para ele podiam ser uma opção desejável, e funcionar mesmo como um substituto, à cosmopoliteia da utopia platônica. Fazendo um balanço geral, Jonas diz: "O fato de que hoje as pessoas se encontram, discutem, informam-se e concordam em um nível internacional me dá coragem. À perspectiva de uma kosmopoliteia vinculo hoje uma maior esperança do que há quinze anos, à época da publicação de meu livro 'Das Prinzip Verantwortung"

Mas a esperança de Jonas - a pouca que lhe restava e que para ele deve permanecer - recaía, por fim, não sobre "políticos, presidentes de comitês, e assim por diante, detentores de poder, mas (antes) sobre todos nós", pois, segundo ele, "não somos totalmente impotentes [...] temos algum controle sobre como nos comportamos. Não estamos totalmente a mercê das forças do mercado"60. Jonas ainda acredita que através da educação

podemos ter uima influiência na formação dos nossos hábitos de consuimo e fazer com que certa frugalidade, uma maior modéstia, se torne parte do clima social ou, por outro lado, imponha certa vergonha, uma difamação social em relação ao hedonismo excessivo e vulgar, ao consumismo do tipo imoderamente hedonístico ${ }^{61}$

A legislação apenas acompanharia essa mudança do estilo de vida. Jonas certamente teria visto com bons olhos as manifestações mundiais em favor do ambiente que aconteceram no último dia 20 de setembro de 2019.

Para alguns, Jonas foi, com sua heurística do temor, apenas um profeta do apocalipse, um tecnofóbico. Isto não é justo. E fica ainda mais claro se se entende que a heurística do temor é uma profecia do pior, e como tal ela é uma ação tática. A profecia é certamente, aos olhos do próprio Jonas, um ação de tal estirpe. Ela não é uma ingênua previsão do futuro, mas busca construir o futuro a partir de seu alerta. As contribuições de Jonas para a disciplina ética não podem ser subestimadas, e já possuem profundo impacto no metabolismo político do globo, conforme o atesta o discurso das autoridades dos diversos países representados na Rio+20. É bem verdade que a Rio+20 endossou explicitamente, entretanto, não o princípio responsabilidade (PR), e sim o princípio de

${ }^{57}$ JONAS, Dem bösen Ende näher, op. Cit., 1993, 41-42.

58 Ibidem, p. 42. Isto não é, como dissemos, um passo atrás: já no ensaio "Wertfrei Wissenschaft und Verantwortung" Jonas falava de "um verdadeiro "conselho de sábios", como os reis-filósofos do "Estado" de Platão - uma concepç̃̃o utópica em si mesma, e irreal inclusive se, contra toda probabilidade, ocorresse em algum lugar uma coisa assim. Porque dado que os problemas são múltiplos e globais, o Estado correspondente teria de ser um Estado mundial: de outro modo, até os esclarecidos sábios em sua terra de ninguém, na qual desfrutam de autoridade, se encontrariam sob a pressão do que se faz em outra parte" (JONAS, Technik, Medizin und Ethik, op. Cit. p. 79). Note-se que Jonas mostra aqui algo de uma descrença quanto a tal possibilidade, que se tornou mais tangível com o passar do tempo, embora ainda esteja longe de se concretizar. ${ }_{59}$ Hoffnung auf eine Kosmopoliteia. Vermeidung des Summum malum in der globalisierten Marktwirtschaft. Hans Jonas im Gespräch mit Siemens-Mitarbeitem und dem Theologen Professor Hans-Joachim Türk (21. Juli 1991). In: BAUSCH, Thomas und BÖHLER, Dietrich (Hrsg.). 2000. Zunkunftsverantwortung in der Marktwirtschaft in memoriam Hans Jonas. Münster: Lit, 2000, p. 21-30 [p. 30].

${ }^{60}$ JONAS, Hans. The Consumer's Responsibility. In: OFSTI, A. (Ed.). Ecology and Ethics: A report from the Melbu Conference, 18-23 July 1990. Trondheim: Nordland Akademi for Kunst og Vitenskap, 1992, p. 215-218 [p. 217].

${ }^{61}$ Ibidem, p. 217. 
precaução (PP). Mas não se deve esquecer que o PP é parte do $\mathrm{PR}$, e nesse sentido o princípio responsabilidade se encontra, de certo modo, acolhido. Ao contrário do que facilmente se pode pensar, o PR não é a afirmação de uma ética prudencial (em sentido estritamente aristotélico), e sim uma ética da precaução ${ }^{62}$.

Como visto, foi pensando em "conferências internacionais" como a Rio+20, das quais Jonas teve conhecimento - por exemplo, na RIO1992 -, que ele alimentou maior esperança na descoberta de soluções. Mas há quem possa pense, entretanto, que toda essa mudança não teve efeito prático real, isto é, o reconhecimento do problema do aquecimento global, por exemplo, não acarretou uma mudança de comportamento. Yuval Harari é dessa opinião. Segundo ele, os dados de emissões para a pesquisa atmosférica global, da comissão europeia, revelam que "as conferências, cúpulas e protocolos não conseguiram restringir o efeito estufa das emissões globais", pois "as emissões somente se reduzem durante períodos de crise econômica e estagnação"63. Mas apesar de uma suspeita como essa ser sempre considerável, é preciso também se perguntar: e se não tivessem ocorrido tais conferências, cúpulas e protocolos, a taxa de emissões não teria sido ainda maior? O aumento das emissões não seria ainda mais acentuada? Seja como for, além desse, outro fator que coloca em questão a efetividade da profecia jonasiana é a crescente negação da influência humana sobre o metabolismo global, questionando os dados ambientais como forma de manipulação geopolítica e econômica das fontes de energia. Cada vez mais se ouve - e há que se dizer, não sem argumentos razoáveis como os de Pascal Bernardin em $L^{`}$ Empire écologique, por exemplo - que a querela em torno do buraco da camada de ozônio e o efeito estufa não passam de uma campanha que tem como fundo propósitos mais propriamente econômicos do que ambientalistas. Ademais, quem pôde assistir à Conferência RIO2012, não deve ter deixado passar as reivindicações centrais dos países africanos, que apontaram para o problema de se considerar proporcionalmente os pesos da crise ecológica, e da necessidade dos países abastados ajudarem os mais pobres.

Não nos importa tanto aqui saber quem está com a verdade nessa querela. $\mathrm{O}$ importante é que os dados de aumento das emissões de $\mathrm{CO} 2$ e a querela ideológica em torno do aquecimento global colocam em questão o valor da profecia - no caso de Jonas, a heurística do temor - para a efetivação da reflexão ética.

\section{Considerações finais sobre o profético na filosofia: Kant, Jonas e Heidegger}

Por fim, quero então apenas elaborar brevemente uma avaliação do valor do profético para a atividade filosófica e suas consequências na vida humana. Para tanto, tentarei comparar alguns elementos do uso do profético em Kant e Jonas e depois confrontar seu valor com a crítica heideggeriana à profecia.

Muito bem: cá estamos longe de uma "perfeita unificação civil da espécie humana" tal como fomentada pelo profeta $K$ ant $^{64} \mathrm{e}$, para piorar, a caminho de um suposto possível fim da humanidade, segundo o profeta Jonas. Eis por que este úlltimo inclusive viu a necessidade de pensar a teleologia da natureza para defender não a meta de sua realização plena, mas o dever de existência ou permanência futura da humanidade na terra. A primeira grande diferença do uso do profético em Jonas com o uso que dele o faz Kant é que o caráter profético da narrativa histórica deste último espera o melhor, é um impulso para o melhor, enquanto em Jonas a profecia busca mobilizar o temor pelo pior para que o mesmo não aconteça; trata-se de uma contenção de danos antes que um incentivo ao progresso (moral). A razão dessa diferença se explica pelo fato de que em Jonas o bem está realizado no mundo, em Kant, entretanto, é uma ideia regulativa. Que seja uma ideia regulativa, eis o que pelo menos afasta qualquer

${ }^{62}$ LOPES, Wendell E. S. (2019). A heurística do temor em Hans Jonas. In: Anais XVII Simpósio de Filosofia 16 a 18 de outubro de 2019. Organizaçăo: Aléssio da Rosa. Brusque: Faculdade São Luiz, 2019, p. $28-43$ [p. 37-40].

${ }^{63}$ HARARI, Yuval. (2016). Homo deus. uma breve história do amanhã.. Trad. de Paulo Geiger. São paulo: Companhia das Letras, 2016, p. 222.

${ }^{64}$ KANT, Kants Werke B. VIII, op. Cit., p. 29. 
aproximação de Kant com o messianismo utópico dos movimentos políticos que se seguiram depois dele.

A segunda diferença a se enfatizar concerne ao aspecto epistemológico envolvido na profecia filosófica. Enquanto Kant encontra uma experiência passada ou mesmo presente que permita a antecipação profética capaz de predizer o futuro - no caso dele, a revolução francesa é o signo indicador para a consolidação do republicanismo -, Jonas, por sua vez, ollha para uma possível catástrofe resultante da ação tecnológica a nos ameaçar no futuro; é o signo do desastre futuro, portanto, que promete o pior a ser evitadlo. $O$ temor está relacionado sempre a uma ameaça futura possível. E a antecipação dessa ameaça é obra da îmaginação. Mas embora a fonte do temor heurístico seja imaginativa, isto não significa que aquilo que se antecipa não tenha qualquer elo com a experiência ${ }^{65}$. A futurologia sempre parte - ou pelo menos deveria partir - de dados científicos concretos.

Uma última diferença que gostaria de deixar indicada está relacionada com o fato de que enquanto para Kant, depois do avanço, isto é, a visão gloriosa do republicanismo, a consciência humana não retrocede, para Jonas, entretanto, a técnica moderna demanda vigilância constante, e a consciência ecológica despertada pelo temor diante da possível catástrofe não é uma conquista definitiva, nem necessariamente uma expressão de modificação do pensar. Sobre isso terei mais o que dizer a seguir.

Uma coisa, entretanto, é certa: a preocupação com o futuro é um forte elemento legado pela consciência histórica na reflexão filosófica que desgarra da modernidade, e o recurso à profecia aparece em Kant e Jonas como resultado deliberado diante dessa vívida consciência histórica. Aliás há que se dizer que depois de Kant, o problema da história passa a ganhar uma importância decisiva, recebendo em Hegel sua valorização máxima que permanecerá evidente pelo menos na tradição continental da filosofia. Como se sabe, Heidegger em especial concentrou toda a força de seu pensamento tardio à questão da história do Ser. Interpretou essa história como uma história do esquecimento do Ser, e a metafísica, agora em seu fim, com a tecnociência, como a razão para esse esquecimento. Em contraposição, entretanto, ele vislumbrou por sua parte a possibilidade de um novo início para o pensar. Mas uma vez o futuro ganha a importância para a filosofia. Mas agora o filósofo da floresta negra tem uma nova relação com ele. Aqui a profecia não aparece mais como recurso. Heidegger caminha numa direção diferente daquelas de Kant e Jonas a esse respeito. Na sua entrevista para a revista Der Spiegel, diz ele:

Não se trata apenas de esperar até que, daqui a 300 anos, o homem chegue a descobrir algo. Trata-se antes de prospectar/pensar adiante [vordenken] os tempos que hão-de vir, sem pretensões de profecia, a partir das linhas fundamentaís e quase impensadas da era actual. O pensar não é inatividadé é ele mesmo o agir [Handeln] que, em si mesmo, está em diálogo com o destino do mundo [Weltgeschick]. A mim me parece que a distinção entre teoria e praxis, de

\begin{abstract}
${ }^{65}$ Frogneux pensa que "Jonas não fala de ameaça imaginada, mas de ameaça antecipada ou representada e propõe lançar-se a experiências de pensamento que permitam ampliar nosso saber filosófico, eliminando certas questões inúteis e vãs. Na verdade, não se trata de dar livvre curso a uma imaginaç̃̃o inventiva delirante que nos deixaria rendidos a imagens falsas ou fantasias para recorrer à representação. $\hat{E}$, aliás, porque o saber ideal dos princípios e o saber empírico dos possíveis ou reais se corrigem mutuamente, que as experiências de pensamento apresentam uma pertinência real para a aquisição de um saber filosófico concernente aos fundamentos da ética" (FROGNEUX, O Medo como Virtude de Substituição, op. Cit " p. 189). Mas é preciso dizer que Frogneux demonstra ter aí uma concepção equivocada da faculdade imaginativa, e ao jogar todo o seu preconceito a respeito dessa faculdade que é vista como fantasiosa e mesmo "delirante", ela tenta afastar a heurística do temor de qualquer relação com ela. Mas basta se pensar: que faculdade antecipa possibilidades ou projeta mundos possiveis? A razão? Certamente não! E mais ainda para Jonas, para quem a própria razão é apenas um desdobramento da livre imaginação. Bernard Sève, entretanto, percebeu bem que "para antecipar uma ameaça, quer dizer, para nos darmos uma representação concreta e determinada de um mal que ainda não existe, é preciso uma faculdade de imaginação pouco comum". Mais: precisamente por não separar imaginação e representação, diz ele, "o elemento do sentimento, que faz do medo uma paixão enérgica e produtiva, deve ser produzido a partir da representação e, por assim dizer, somado à representação" (Sève, 1992, p. 113).
\end{abstract}


proveniência metafísica, e a representação de uima transmissão entire ambas destroçam o caminho que conduz àquilo que eu entendo como pensar ${ }^{66}$.

O novo pensar de Heidegger enquanto pensamento da história do ser não apenas se volta para o passado na forma de um memento (Andenken), mas também lança o olhar para o futuro, numa verdadeira prospecção (Vordenken) sem intenção profética. A profecia que o filósofo condena aqui é uma profecia mais ao estilo de Kant, e não tanto ao estilo de Jonas. De qualquer modo, a relação com o futuro não é aquele que visa operar uma mudança em seu acontecer, mas antes a de uma exploração do sentido do nosso ser futuro enquanto articulável no discurso, tendo em vista a memória que carregamos de nosso passado. É só essa articulação temporal do pensar que pode nos encaminhar num destino diferente daquele que nos enredamos inadvertidamente. Para Heidegger, teoria e prática, pensar e ser, não se separam. E apenas uma nova revolução no pensar pode alterar o destino do ser. Quando Jonas aposta na educação enquanto modificação da mentalidade como forma de contenção da debanda tecnológica, algo da ideia heideggeriana está em jogo. Mas pode a heurística do temor, este recurso ao profético na filosofia, servir de instrumento igualmente transformador de nossa existência?

As diversas conferências internacionais como a Rio+20 talvez possam conter certos desenvolvimentos; as manifestações mundiais do dia 20 de setembro de 2019 mostraram que a consciência ecológica ganhou expressão pública. $\mathrm{E}$ isso é em parte expressão da obra de profetas da catástrofe como Jonas! Mas tudo isto é demonstração de uma real alteração do pensar? É a aurora de um novo pensar que não o pensar calculativo da tecnociência, ou é novamente um movimento de massa que atende inadvertidamente - e isto quer dizer: sem uma verdadeira modificação do pensar - a novas forças políticas, econômicas e tecnocientíficas?

Aqui não cabe lançar Heidegger contra Jonas a respeito do valor da profecia. $O$ que ambos fizeram, cada um a seu modo, teve um resultado que Andrew Feenberg chamaria de tático contra a estratégia da civilização tecnológica. Para Jonas, estava bem claro que Heidegger percebeu a necessidade de uma nova ética para a civilização tecnológica que esteja à altura das exigências do momento e "buscou fazer-lhe frente, ainda que também isto que ele tinha a dizer a respeito, a especulação sobre o destino do espírito no Ocidente, que desde os pré-socráticos se distanciou da verdade autêntica, parece-me totalmente equivocado" 67 .

Podemos ficar do lado de Heidegger ou de Jonas e Kant acerca do papel do profético na filosofia. Sobre o uso da profecia filosófica no caso de Jonas, não me parece equivocado dizer que, embora alguns sistemas complexos - como, por exemplo, o clima sejam indiferentes às predições, a história humana, entretanto, sempre mostrou-se reativa a profecias. Estas têm efeitos. O caso das ficções científicas que impulsionaram invenções é exemplar a esse respeito; funcionam como verdadeiras profecias. Jonas depositou sua confiança nesse procedimento. Não se pode falar aqui de ingenuidade. Muito pelo contrário: estava em jogo uma profunda consciência da problemática da efetividade de uma reflexão ética. É certo que essa astúcia tática de Jonas o afasta da crítica de tecnofobia, bem como do que Kant chamara de terrorismo moral, embora flerte perigosamente com o auitoritarismo aristocrático de um Platão. É o mellhor método tático de defesa contra a força estratégica da técnica moderna que vem de cima para baixo? Não sei. De qualquer forma, era apenas um elemento prático a mais da responsabilidade filosófica ${ }^{68}$ (cf. JONAS, 1993b, p. 42-43), que reclama um vínculo indissociável entre razão

${ }^{66}$ HEIDEGGER, Martin. (2000). Spiegel-Gespräch mit Martin Heidegger (26. September 1966). In: Gesamtausgabe, B. 16. Reden und andere Zeugnisse eines Lebensweges. Hg. v. Hermann Heidegger. Frankfurt/M, Klostermann, 2000, S. 652-683 [p. 675 grifos meus].

${ }^{67}$ JONAS, Erinnerungen, op. Cit., p. 323.

68 cf. JONAS, Hans. Philosophie: Rückschau und Vorschau am Ende des Jahrhunderts. Frankfurt am Main: Suhrkamp, 1993, p. 42-43. 
teórica e razão prática. Para Jonas também a filosofia precisa provar-se uma prática da vida.

\section{Referências}

APEL, K-O. Macroethics, Responsability for the future and the crisis of technological Society: reflections on Hans Jonas. In: Karl-Otto Apel: selected essays. New Jersey: Humanities Press, 1996, p. 219-243.

BERNARDIN, Pascal. L'Empire écologique: ou la subversion de l'écologie par le mondialisme. Éditions Notre-Dame des Grâces, 1998.

BERTI, Enrico. Il Neo-aristotelismo di Hans Jonas. Iride, nº 6, janvier-juin 1991, p. 227231.

BÖHLER, Dietrich. Em la duda a favor de la responsabilidad y de la vida. A la memória de Hans Jonas (1903-1993). Paradoxa, 10, Octubre, 2003, p. 13-65.

Einleitender Kommentar. In: Kritische Gesamtausgabe der Werke von Hans Jonas, B. III/2. Freiburg i. Br./Berlin/Wien: Rombach, 2013, p. Xvii-Xxxix.

FROGNEUX, Nathalie. O Medo como Virtude de Sulbstituição. In: NOVAES, Adauto (Org.). Ensaios sobre o medo. São Paulo: Ed. SENAC São Paulo: Edições SESC SP, 2007, p. $187-207$.

GADAMER, Hans-Georg. Hans-Georg Gadamer und Hans Jonas: Briefe uiber die Zukunftsethik. In: Orientierung und Verantwortung: Begegnungen und Auseinandersetzungen mit Hans Jonas. Dietrich Böhler und Jens Peter Brune [Hrsg.]. Würzburg: Königshausen und Neumann, 2004, S. 479-482.

HARARI, Yuval. Homo deus. uma breve história do amanhã. Trad. de Paulo Geiger. São paulo: Companhia das Letras, 2016.

HEIDEGGER, Martin. Spiegel-Gespräch mit Martin Heidegger (26. September 1966)。 In: Gesamtausgabe, B. 16: Reden und andere Zeugnisse eines Lebensweges. Hg. v. Hermann Heidegger. Frankfurt/M, Klostermann, 2000, S. 652-683.

JONAS, Hans. Acting, Knowing, Thinking: Gleanings from Hannah Arendt's philosophical work. Social Research, v. 44, ํํ1, 1977, p. 25-43.

- Toward a philosophy of technology. In: SCHARFF, Robert C. \& DUSEK, Val (Ed.). Philosophy of technology. the technological condition: an anthology. Malden: Blackwell Publishing, 2004, p. 191-204.

Das Prinzip Verantwortung. Versuch einer Ethik für die technologische Zivilisation. Frankfurt am Main: Suhrkamp, 1984.

The Imperative of Responsibility. in search of an ethics for the technological age. Chicago: The University of Chicago Press, 1984.

. Warum wir heute eine Ethik der Selbstbeschränkung brauchen" (In: STRÖCKER, Elisabeth (Hrsg.). Ethik der Wissenschaften? Philosophische Fragen. Munchen Paderborn, W. Fink-F. Schöningh, 1984, p. 75-86.

Technik, Medizin und Ethik. zur Praxis des Prinzips Verantwortung. Frankfurt am Main: Sulhrkamp, 1987. 1987.

Wissenchaft als Persönliches Erlebnis. Göttingen: Vandenhoeck \& Ruprecht,

The Consumer's Responsibility. In: OFSTI, A. (Ed.). Ecology and Ethics. A report from the Melbu Conference, 18-23 July 1990. Trondheim: Nordland Akademi for Kunst og 
Vitenskap, 1992, p. 215-218.

Fatalismus wäre Todsünde. In: BÖHLER, Dietrich. und NEUBERTH, Rudi (Hrsg.). Herausforderung Zunkunftsverantwortung: Hans Jonas zu Ehren. Münster: Lit, 1993, p. $49-51$.

. Philosophie Rückschau und Vorschau am Ende des Jahrhunderts. Frankfurt am Main: Sulhrkamp, 1993.

- Dem bösen Ende näher: Gespräche über das Verhä̈ltnis des Menschen zur Natur/ Hrsg. Wolfgang Schneider. Frankfurt am Main: Suhrkamp, 1993.

. The Outcry of Mute Things (January 1993) In: Mortality and Morality. a search for good after Auschwitz. Ed. Lawrence Vogel. Evanston, Illinois: Northwestern University Press, 1996, p. 198-202.

Hoffnung auf eine Kosmopoliteia. Vermeidung des Summum malum in der globalisierten Marktwirtschaft. Hans Jonas im Gespräch mit Siemens-Mitarbeitern und dem Theologen Professor Hans-Joachim Türk (21. Juli 1991). In: BAUSCH, Thomas und BÖHLER, Dietrich (Hrsg.). 2000. Zunkunftsverantwortung in der Marktwirtschafto in memoriam Hans Jonas. Münster: Lit, 2000, p. 21-30.

An Interview with Professor Hans Jonas (By Harvey Scodel). Social Research 70, $n^{\circ} 2$, Summer 2003, p. 339-68.

Erinnerungen: Nach Gesprächen mit Rachel Salamander. Frankfurt am Main: Insel Verlag, 2003.

Matéria, espírito e criação. Trad. de Wendell E. S. Lopes. Petrópolis: Vozes, 2010.

Kritische Gesamtausgabe der Werke von Hans Jonas, B. III/2. Freiburg i. Br./Berlin/Wien: Rombach, 2013.

KANT, Immanuel. Kant's Werke Akademie-Textausgabe, B. VII. Berlin: Walter de Gruyter \& Co., 1968. 1968.

. Kant's Werke: Akademie-Textausgabe, B. VIII: Berlin: Walter de Gruyter \& Co.,

KASS, Leon. Appreciating the Phenomenon of Life. Graduate Faculty Philosophy Journal, จ. 23, n. 1, 2001, p. 51-69.

LOPES, Wendell E. S. A heurística do temor em Hans Jonas. In: Anais XVII Simpósio de Filosofia 16 a 18 de outubro de 2019. Organização: Aléssio da Rosa. Brusque: Faculdade São Luiz, 2019, p. 28-43.

POMMIER, Eric. Life and Anthropology: A Discussion between Kantian Criticism and Jonasian Ontology. Giornale Critico di Storia delle Idee, n. 14, 2015, p. 123-136.

RUBENSTEIN, Alain. Judaism and nature: Reviewing the Jewish Dimensions of Hans Jonas. Religious Studies Review, vol. 36, n. 1, 2010, p. 15-21.

SCHÜTZE, Ch. The Political and Intellectual Influence of Hans Jonas. The Hastings Center Report, V. 25, n 7, p. 40-44, 1995.

SEVE, Bernard. La peur comme procedée heuristique et comme instrument de persuasion. HOTTOIS, G. \& PINSART, M.-G (Éds.). Aux Fondements de la Ethique $\mathrm{H}_{\text {. }}$ Jonas et H. T. Engelhardt. Paris: Vrin, 1992, p. 107-125.

WIESE, Christian. The life and thought of Hans Jonas. Jewish dimensions. Trad. Christian Wiese and Jeffrey Grossman. Hanover/London: University Press of New England, 2007.

VOLPI, Franco. "Le Paradigme Perdu": l'éthique contemporaine face à la technique. 
HOTTOIS, G. (Éd.). Aux Foundaments de la Ethique: H. Jonas et H. T. Engelhardt. Paris: Vrin, 1992, p. 163-179.

Doutor em Filosofia (UFMG)

Professor Adjunto do Departamento de Filosofia da UFMT

Professor do PPG Filosofia/UF'MT

E-mail: wendellsoareslopes@gmail.com 